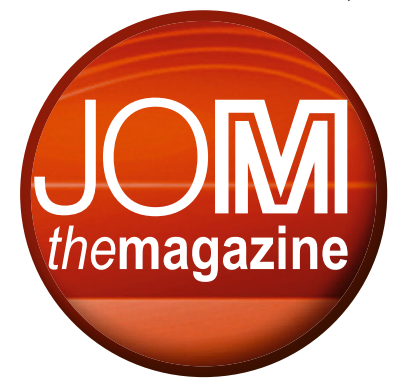

\title{
TMS Leaders Discuss Materials Education in the U.K.; Oral History Project on Mining and Materials
}

\section{new and noteworthy at TMS}

Turn to this regular JOM feature for information on new TMS initiatives, updates and overviews of TMS activities, and news from the field that impacts TMS and its members. To submit news items for consideration, contact Lynne Robinson, JOM Contributing Editor, at Irobinson@tms.org.

\section{TMS Leaders Exchange STEM Outreach Ideas in the U.K.}

Stanley M. Howard, 2016 TMS

President, and James J. Robinson, TMS

Executive Director, joined more than

130 scientists and engineers at the 8 th

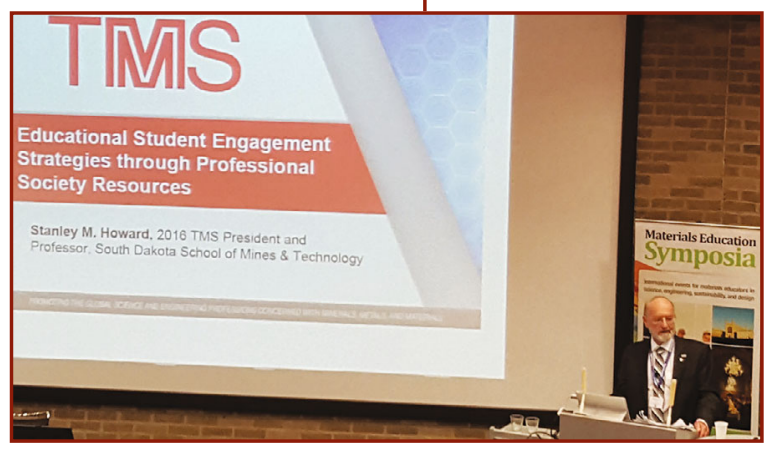

International

Materials Education

Symposium at

the University

of Cambridge,

United Kingdom

(U.K.), in April.

Coordinated by

Granta Design, this

year's symposium

explored innovative

Stanley M. Howard, 2016

TMS President, gave

an overview of student

engagement initiatives offered by TMS at the 8th

International Materials

Education Symposium. approaches to excite and inspire students in materials science, engineering, and design.

Howard gave a talk on TMS programs and initiatives to more fully engage college students in the life of the society as a means of encouraging them to participate

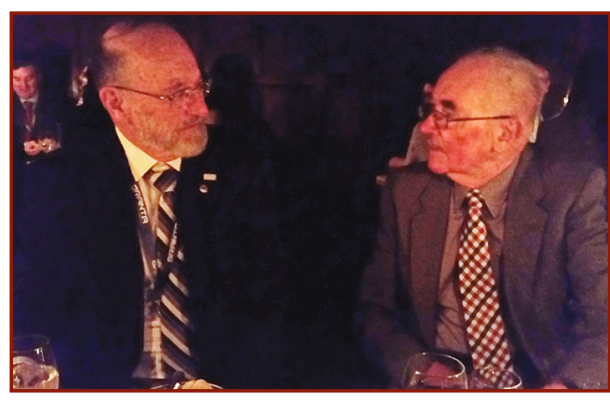

Stanley M. Howard and Michael F. Ashby, Emeritus Professor of Materials, Cambridge University, continue conversations started in the Materials Education Symposium sessions over dinner. Ashby is chair of the symposia series's academic advising committee. in professional society membership as they develop their careers. He first discussed TMS's involvement in the Material Advantage program that offers a single low-cost student membership to four professional societies-TMS, ASM International, The American Ceramic Society, and the Association for Iron \& Steel Technology.

Howard then went on to highlight a number of TMS-specific student programs. These included the Materials Bowl, a question-and-answer competition on science and engineering topics held at every TMS annual meeting; the student run symposium supported by the TMS
Education Committee; and the popular Bladesmithing Competition that challenges student teams to produce a knife or sword blade by hand hammering or trip hammer forging. He concluded his presentation with a brief overview of the TMS Young Leaders program and the resources it offers to smooth the transition from school to the professional world. "Our younger members are infusing our community with new ideas, abilities, and interests," Howard said. "It is critical, both to the future of TMS and the profession that we serve, that we nurture this trend by helping students appreciate the value of professional engagement to their careers after they graduate."

Robinson also participated in the symposium program by presenting a poster on the outcomes of Comic-tanium ${ }^{\mathrm{TM}}$, TMS's recent outreach effort that uses the mythologies of comic characters to attract young people to STEM (science, engineering, mathematics and technology) careers.

Other symposium speakers gave presentations on open on-line teaching techniques, project-based learning, and effective deployment of new information and learning technologies. A report of the symposium can be downloaded at http ://www.materials-education.com/index.htm.

Prior to participating in the Materials Education Symposium, Howard and Robinson visited TMS members at the University of Oxford for a briefing on the Department of Materials' outreach efforts to both high school educators and students. The program offers a suite of professional development courses for teachers that provide guidance and resources on using 
concepts of materials science as a means of satisfying curriculum requirements. Studentfocused activities range from classroom visits, to open days at the materials science laboratories and facilities at Oxford, to more in-depth residential programs.

George Smith, Emeritus Professor of Materials, Oxford, shared the history of the program, having led the development of it when he was department chair in the year 2000. He noted that a critical factor in the program's success was actively listening to the needs and concerns of teachers in managing their requirements. "They requested that we not ask them to do anything new, but instead help them do what was expected of them," he said. For additional information on Oxford Materials Outreach, visit http://outreach .materials.ox.ac.uk/index.php.

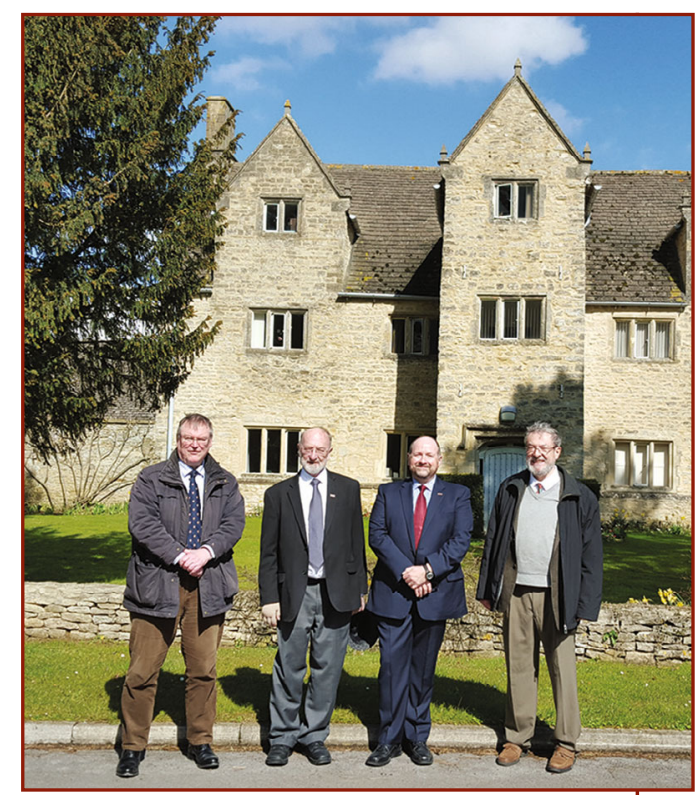

(Left to right) Chris Grovenor, professor, Department of Materials, Oxford University, led Stanley Howard and James Robinson on a tour of Oxford's Begbroke Science Park. George Smith, Emeritus Professor of Materials at Oxford, hosted Howard and Robinson on the daylong visit to the university that included a briefing on its student outreach initiatives.

\section{Posters Recognized for Excellence at 3DMS 2016}

Congratulations to the following individuals who received top honors for their posters at the 3rd International Congress on 3D Materials Science (3DMS), held in St. Charles, Illinois, July 10-13, 2016:

\section{Professional Category}

1st Place:

"3D Grain Reconstruction Using Laboratory-based Diffraction Contrast Tomography"

Yubin Zhang, Technical University of Denmark; A. Lyckegaard, Xnovo Technology ApS; P. Reischig, Xnovo Technology ApS; C. Holzner, Carl Zeiss X-ray Microscopy, Inc.; and E. Lauridsen, Xnovo Technology ApS

\section{2nd Place}

"3D Predictions of Additive Manufactured Microstructures Using a Modified Potts Kinetic Monte Carlo Approach"

Theron Rodgers, Jonathan Madison, and V. Tikare, Sandia National Laboratories
Student Category

1st Place

"A Framework for Modeling Microstructural Characterization Errors and Their Effect on the Accuracy of Grain Ensemble Statistics" Gregory Loughnane, Mound Laser \& Photonics Center, Inc.; Michael Uchic and Michael Groeber, Air Force Research Laboratory

2nd Place

"A New In-Situ Far-Field High Energy Diffraction Microscopy Planar Biaxial Experiment"

Garrison Hommer, Colorado School of Mines; Jun-Sang Park, Argonne National Laboratory; Peter Collins, Iowa State University; Adam Pilchak, Air Force Research Laboratory; Aaron Stebner, Colorado School of Mines

\section{Engineering Competency Model Receives Top Honors}

The American Association of Engineering Societies (AAES) has received a 2016 American Society of Association Executives (ASAE) Power of A Gold Award for its Engineering Competency Model. The model was created as a guideline for the development of professionals in the engineering workforce. The American Institute of Mining, Metallurgical, and Petroleum Engineers (AIME), of which TMS is a member society, is a member of AAES.

Jeffrey W. Fergus, Director, Professional Development on the TMS Board of Directors and professor and associate dean at Auburn University, was one of ten subject matter experts who worked collaboratively to identify and review competencies that would contribute to success in engineering careers. "The model has a tiered structure that begins with competencies common among many disciplines and builds to competencies specific to engineering," said Fergus. "Grouping of competencies that are common among different disciplines is useful to identify opportunities for career transitions and to guide training and education."

An interactive version of the model is available online at www.careeronestop.org/CompetencyModel/competencymodels/engineering.aspx. 


\section{Oral Histories Explore Mining and Materials Industry}

TMS members figure prominently in sharing insights about the evolution of the mining and materials industry over the past 40 years as participants in the Global Mining and Materials Research Project. The initiative entailed recording and posting interviews with eleven experts and leaders in an oral history resource center housed by the Bancroft Library of the University of California, Berkeley. The interviews are now available for free download and viewing at http:/www.lib .berkeley.edu/libraries/bancroft-library /oral-history-center/global-mining.

TMS interviewees include:

- Diran Apelian, 2008 TMS President,
Alcoa-Howmet Professor of Engineering, and Founding Director of the Metal Processing Institute, Worcester Polytechnic Institute.

- Alex King, Director, Critical Materials Institute, Ames Laboratory

- Thaddeus Massalski, Professor Emeritus of Materials Science, Engineering and Physics, Carnegie Mellon University

- Alexander Scott, retired TMS Executive Director

AIME is a collaborator on the project, which is part of the Engineering and Technology History Wiki (ETHW), accessed at ethw.org.

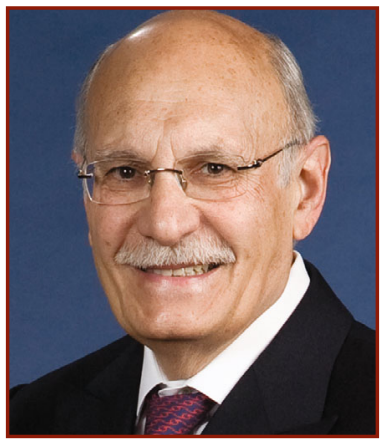

Diran Apelian

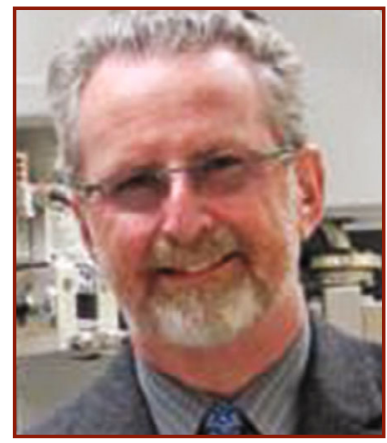

Alex King

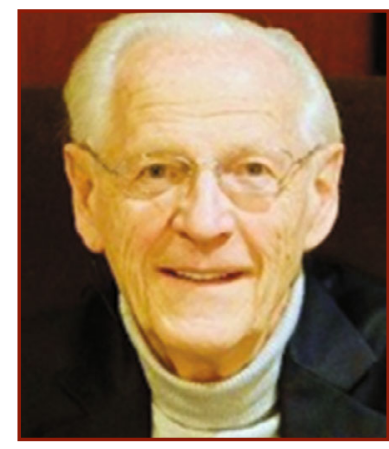

Thaddeus Massalski

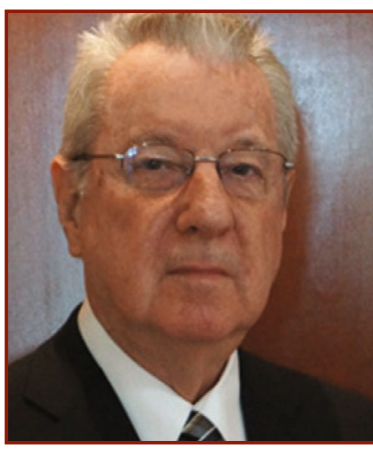

Alexander Scott

\section{TMS Welcomes New Members}

Please join TMS in congratulating the following new members, approved by the TMS Board of Directors at its July 2016 meeting:

Banyash, Dan; BASF Corporation, United States

Behera, Narottam; SABIC, Saudi Arabia

Bennett, James P.; National Energy Technology Laboratory, United States

Bhagat, Rohit; WMG University of Warwick, United Kingdom

Bielefeldt, Wagner Viana; Federal University of Rio Grande do Sul, Brazil

Billet, Beau A.; Ohio State University, United States

Brown, Yasmin R.; Jacobs Consultancy Incorporated, United States

Chen, Jeff (Jiang); University of Queensland, Australia

Chung, Tae In; POSCO, Korea, South

Chun, Yongsug; Korea Polytechnic University, Korea, South
Clayton, Christopher K.; Pacific Northwest National Laboratory; United States

Cline, John K.; Vectren Corporation, United States

Collins, Sunniva R.; Case Western Reserve University, United States

Coulon, Antoine; France

Crivits, Tijl; Umicore, Belgium

De Wilde, Evelien; Umicore, Belgium

Desai, Bhavin; Aditya Birla Science and Technology, India

Dubberstein, Tobias; TU Bergakademie Freiberg, Germany

Duchesne, Marc; Natural Resources Canada, Canada

Erwee, Markus W.; Mintek, South Africa

Essack, Saskia; Tenova Minerals (Pty) Ltd., South Africa
Fan, Yong; Japan

Fan, Youqi; Anhui University of Technology, China

Fujii, Yusuke; JFE Steel Corporation, Japan

Gaal, Sean G.; Dow Corning, United States

Garbers-Craig, Andrie M.; University of Pretoria, South Africa

Glaser, Bjoern; Royal Institute of Technology (KTH); Sweden

Goldman, Rachel S.; University of Michigan, United States

Goso, Xolisa; Mintek, South Africa

Govindaraju, Madhavrao; SAI Global Technologies Incorporate, United States

Greene, Michael; Imerys, United States

Gu, Yuping; China

Guo, Muxing; MTM KU Leuven, Belgium 
Guoxing, Ren; China

Haccuria, Elien; Umicore, Belgium

Han, Yong-Uk; Yonsei University, Korea, South

Hayashi, Miyuki; Tokyo Institute of Technology, Japan

Heller, Hans-Peter; TU Bergakademie Institute Iron and Steel, Germany

Henao, Hector Mario; Technical University Federico Santa Maria, Chile

Henderson, Brooks; United States

Herling, Darrell R.; Pacific Northwest National Laboratory, United States

Hidayat, Taufiq; Pyrosearch Group, Australia

Holappa, Lauri Elias K.; Aalto University, Finland

Hu, Meilong; Chongqing University, China

$\mathrm{Hu}$, Xiaohua; Pacific Northwest National Laboratory, United States

ljawhari, Hala; Saudi Arabia

Inoue, Ryo; Akita University, Japan

Jang, Eunhack; Pohang University of Science and Technology, Korea, South

Jiang, Tao; Northeastern University, China

Kang, Seongwon; LS-Nikko Copper Incorporate, Korea, South

Kaplan, Valery; Weizmann Institute of Science, Israel

Karbowniczek, Miroslaw; AGH University of Science and Technology, Poland

Kim, Wan-Yi; Korea, South

Kobayashi, Yoshinao; Tokyo Institute of Technology, Japan

Kondratiev, Alex; National University of Science and Technology, Russian Federation

Kwong, Kyei-Sing; National Energy Technology Laboratory, United States

Lee, Joonho; Korea University, Korea, South Leuchtenmueller, Manuel; Austria

Li, Xiuyan; Institute of Metal Research, Chinese Academy of Sciences, China

Lindberg, Daniel K.; Åbo Akademi University, Finland

Lu, Zhaoping P.; University of Science and Technology, China

Luo, Xuetao; Xiamen University, China

Lv, Xuewei; Materials Science, China

Maheshwari, Prateek; Punjab Engineering College, India

Malfliet, Annelies; Katholieke Universiteit Leuven, Belgium
Marotta, Michael; United States

Marschall, Irmtraud; K1-MET GmbH, Austria

Mendoza, Alvaro G.; Precision Castparts Corporation Structurals, United States

Min, Dong Joon; Yonsei University, Korea, South

Monaghan, Brian J.; University of Wollongong, Australia

Nakano, Junichiro; National Energy Technology Laboratory, United States

Nakashima, Kunihiko; Japan

Natsui, Shungo; Hokkaido University, Japan

Nishi, Tsuyoshi; Japan

Nohira, Toshiyuki; Kyoto University, Japan

Nurni, Viswanathan N.; Indian Institute of Technology Bombay, India

Odei, Henry; Cote d'Ivoire, West Africa

OMalley, Ronald J.; Missouri University Science and Technology, United States

Park, Jeong Hyouk; Samil Stollberg Company, LTD. Korea, South

Park, Kwangsuk; Korea Institute of Industrial Technology, Korea, South

Park, Min-seok; Pohang University of Science and Technology, Korea, South

Park, Youngjoo; Yonsei University, Korea, South

Pelletier, Colin M.; RSR Technologies, United States

Peterson, Elizabeth I.; Missouri University of Science \& Technology, United States

Pletcher, Ben A.; United States

Qu, Guibao; Chongqing University, China

Rahnama, Alireza; University of Warwick, United Kingdom

Raj, Baldev; National Institute of Advanced Studies, India

Raman, R.K. Singh; Monash University, Australia

Ringdalen, Eli; SINTEF, Norway

Saito, Noritaka; Kyushu University, Japan

Salgado, Janette; Alcoa, United States

Scheunis, Lennart; Umicore N.V., Belgium

Shevchenko, Maksym; University of Queensland, Australia

Shi, Zengmin; Huazhong University of Science and Technology, China

Snyder Timothy M.; Aleris, United States

Somerville, Michael; Commonwealth Scientific and Industrial Research Organization, Australia

Son, Sanghan; POSCO, Korea, South

Song, Shengqiang; University of Pretoria,
South Africa

Songwen, Xiao; Changsha Research Institute of Mining Metallurgy Company, LTD, China

Stewart, Bridget $\mathrm{H}_{\text {.; }}$ Materials Processing Institute, United Kingdom

Sturgill, Darrell E.; Imerys Steelcasting, United States

Sukenaga, Sohei; Tohoku University, Japan

Susa, Masahiro; Tokyo Institute of Technology, Japan

Takacs, Laszlo; University of Maryland Baltimore County, United States

Tanahashi, Mitsuru; Nagoya University, Japan

Tashiro, Masanori; Tohoku University, Japan

Topal; Recep; Turkey

Tranell, Gabriella M.; Norwegian University of Science and Technology, Norway

Udomon, Henry; Struers Incorporated, United States

Valkenburg, Michael J.; McMaster University, Canada

Van Gestel, Ron; Netherlands

Van Rensburg, Christelle; BASF, United States

Vermetten, Maxime; Metallo-Chimique, Belgium

Vincke, Joris S.; Metallo Chimique, Belgium

Wang, Lijun; University of Science and Technology, China

Wang, Min; China

Weitz, Heine; OptiProc, South Africa

White, Christina V.; Alcoa Norway AS, Norway

Wittgens, Bernd; SINTEF Materials and Chemistry, Norway

Wollenburg, Nathan; Prince Minerals Incorporated, United States

Yang, Yindong; University of Toronto, Canada

Yao, Lu; University of British Columbia, United States

Yasuda, Kouji; Kyoto University, Japan

Zavatti, Jorge R.; Aluar Aluminio Argentino, Argentina

Zhang, Chen; Baoshan Iron and Steel Company, Ltd., China

Zhang, Mei; University of Science and Technology, China

Zhang, Yanling; University of Science \& Technology Beijing, China

Zietsman, Johan H.; University of Pretoria, South Africa 